J. Nonlinear Var. Anal. 2 (2018), No. 3, pp. 287-294

Available online at http://jnva.biemdas.com

https://doi.org/10.23952/jnva.2.2018.3.04

\title{
STABILITY OF FIXED POINTS IN GENERALIZED METRIC SPACES
}

\author{
ABDUL LATIF ${ }^{1, *}$, TALAT NAZIR ${ }^{2}$, MUJAHID ABBAS $^{3,4}$ \\ ${ }^{1}$ Department of Mathematics, King Abdulaziz University, P.O. Box. 80203, Jeddah 21589, Saudi Arabia \\ ${ }^{2}$ Department of Mathematics, COMSATS Institute of Information Technology, Abbottabad 22060, Pakistan \\ ${ }^{3}$ Department of Mathematics, Government College University, Lahore 54000, Pakistan \\ ${ }^{4}$ Department of Mathematics and Applied Mathematics, University of Pretoria, Lynnwood road, Pretoria 0002, South Africa
}

\begin{abstract}
Let $(X, G)$ be a generalized metric space. Let $\left\{G_{n}\right\}_{n \in \mathbb{N}}$ be a sequence of $G$-metrics on $X$ and let $T_{n}: X_{n} \rightarrow X_{n}$, where $\left\{X_{n}\right\}$ is a sequence of nonempty subsets of $X$, be a $(\psi, \varphi)$-weakly contractive mapping with a fixed point $x_{n}$. In this paper, we study the the convergence of $\left\{T_{n}\right\}$ and the convergence of $\left\{x_{n}\right\}$. Various stability results are established.
\end{abstract}

Keywords. Fixed point; Stability; Altering distance function; $G$-metric space.

2010 Mathematics Subject Classification. 54H25, 47H10, 54E50.

\section{INTRODUCTION}

Recently, Mustafa and Sims [13, 14] introduced generalized metric space (or $G$-metric space) as a generalization of metric spaces where every triplet of an arbitrary set $X$ is mapped into $\mathbb{R}^{+}$(non-negative reals). Subsequently, a number of useful results on fixed and periodic points in these spaces for different classes of mappings were obtained [1, 5, 7, 8, 15, 16, 17, 18, 20, 22]. Barbet and Nachi [2, 3] and Nachi [19] obtained some stability results in a metric space using certain new notions of convergence over a variable domain. These results generalize the corresponding results in Bonsall [4], Fraser and Nadler [6] and Nadler [21]. Recently, Mishra et al. generalized Barbet-Nachi's results in different settings for various classes of mappings; see $[9,10,11,12]$ and the references therein. To the best of our knowledge, stability results have not been studied in the setting of $G$-metric spaces.

Let $(X, G)$ be a generalized metric space. Let $\left\{G_{n}\right\}_{n \in \mathbb{N}}$ be a sequence of $G$-metrics on $X$ and let $T_{n}: X_{n} \rightarrow X_{n}$, where $\left\{X_{n}\right\}$ is a sequence of nonempty subsets of $X$, be a $(\psi, \varphi)$-weakly contractive mapping with a fixed point $x_{n}$. In this paper, we study the the convergence of $\left\{T_{n}\right\}$ and the convergence of $\left\{x_{n}\right\}$. Various stability results are established.

Throughout this paper, $\mathbb{N}$ denotes the set of natural numbers and $\overline{\mathbb{N}}=\mathbb{N} \cup\{\infty\}$. First we recall the following definitions and results from Mustafa and Sims $[13,14]$ which play an important role in this paper.

Definition 1.1. Let $X$ be a nonempty set. Let $G: X \times X \times X \rightarrow \mathbb{R}^{+}$be a mapping satisfying the following conditions:

\footnotetext{
${ }^{*}$ Corresponding author.
}

E-mail addresses: alatif@kau.edu.sa (A. Latif), talat@ ciit.net.pk (T. Nazir), abbas.mujahid@ gmail.com (M. Abbas).

Received February 5, 2018; Accepted May 3, 2018.

(C)2018 Journal of Nonlinear and Variational Analysis 
$\left(\mathbf{G}_{1}\right) 0<G(x, x, y)$ for all $x, y \in X$, with $x \neq y$;

$\left(\mathbf{G}_{2}\right) G(x, y, z)=0$ if $x=y=z$;

$\left(\mathbf{G}_{3}\right) G(x, y, z) \geq G(x, y, y)$ for all $x, y, z \in X$, with $y \neq z$;

$\left(\mathbf{G}_{4}\right) G(x, y, z)=G(z, y, x)=G(z, x, y)=\ldots, x, y, z \in X$;

$\left(\mathbf{G}_{5}\right) G(x, y, z) \leq G(x, u, u)+G(u, y, z)$ for all $x, y, z, u \in X$.

Then $G$ is called a $G$-metric on $X$ and the pair $(X, G)$ is called a $G$-metric space. For simplicity, we us $X$ to stand for the $G$-metric space.

Definition 1.2. [14] A sequence $\left\{x_{n}\right\}$ in a $(X, G)$ is said to be

(i): G-convergent to $x^{*} \in X$ if, for any $\varepsilon>0$, there is an $n_{0} \in \mathbb{N}$, such that, for all $n, m \geq n_{0}$, $G\left(x^{*}, x_{n}, x_{m}\right)<\varepsilon$. This is denoted by $\lim _{n, m \rightarrow \infty} G\left(x^{*}, x_{n}, x_{m}\right)=0$;

(ii): G-Cauchy if, for any $\varepsilon>0$, we have an $n_{0} \in \mathbb{N}$, that is, for all $n, m, l \geq n_{0}, G\left(x_{n}, x_{m}, x_{l}\right)<\varepsilon$. That is, $\lim _{n, m, l \rightarrow \infty} G\left(x_{n}, x_{m}, x_{l}\right)=0$.

Further, if every $G$-Cauchy sequence in $(X, G)$ is $G$-convergent, then $(X, G)$ is called a $G$-complete.

Proposition 1.1. [14] Let $X$ be a G-metric space. The following assertions are equivalent

(1) $\left\{x_{n}\right\}$ is G-convergent to $x$;

(2) $G\left(x_{l}, x_{k}, x\right) \rightarrow 0$ as $k, l \rightarrow \infty$;

(3) $G\left(x_{l}, x_{l}, x\right) \rightarrow 0$ as $l \rightarrow \infty$.

(4) $G\left(x_{l}, x, x\right) \rightarrow 0$ as $l \rightarrow \infty$.

Definition 1.3. [1] Let $X$ be a $G$-metric space. $X$ is said to be symmetric if $G(x, x, y)=G(x, y, y)$, $\forall x, y \in X$.

Proposition 1.2. [14] Let $X$ be a $G$-metric space. Define $d_{G}: X \times X \rightarrow \mathbb{R}^{+}$by

$$
d_{G}(x, y)=G(x, x, y)+G(x, y, y)
$$

for all $x, y \in X$. Then $d_{G}$ is metric on $X$. Note that if $X$ is symmetric $G$-metric, then

$$
d_{G}(x, y)=2 G(x, x, y)
$$

for all $x, y \in X$. If $X$ is non symmetric, then

$$
\frac{3}{2} G(x, x, y) \leq d_{G}(x, y) \leq 3 G(x, x, y)
$$

for all $x, y \in X$.

Example 1.1. [14] Let $X=\{1,2\}$ and $G: X \times X \times X \rightarrow \mathbb{R}^{+}$be defined as

\begin{tabular}{|c|c|}
\hline \hline$(x, y, z)$ & $G(x, y, z)$ \\
\hline \hline$(1,1,1),(2,2,2)$ & 0 \\
$(1,2,1),(1,1,2),(2,1,1)$ & 3 \\
$(1,2,2),(2,1,2),(2,2,1)$ & 6 \\
\hline
\end{tabular}

Here $G$ is a $G$-metric on $X$. Note that $G(1,1,2) \neq G(1,2,2)$. Therefore $G$ is a non symmetric $G$-metric. 
A function $\varphi:[0, \infty) \rightarrow[0, \infty)$ is said to be an altering distance function, if $\varphi$ is increasing and continuous with $\varphi(t)=0$ if and only if $t=0$. Let $X$ be a $G$-metric space. A mapping $T: X \rightarrow X$ is said to be $(\psi, \varphi)$-weakly contractive if it satisfies

$$
\psi(G(T x, T y, T z)) \leq \psi(G(x, y, z))-\varphi(G(x, y, z)), \quad \forall x, y, z \in X,
$$

where $\psi$ and $\varphi$ are altering distance functions.

If $\psi(t)=t$ in (1.1), then $T$ is said to be weakly contractive, that is,

$$
G(T x, T y, T z) \leq G(x, y, z)-\varphi(G(x, y, z)), \quad \forall x, y, z \in X .
$$

Furthermore, if $\varphi(t)=(1-\lambda) t$ for $\lambda \in[0,1)$ and $\psi(t)=t$ in (1.1), then $T$ is said to be $\lambda$-contractive, that is,

$$
G(T x, T y, T z) \leq \lambda G(x, y, z), \quad \forall x, y, z \in X .
$$

Barbet and Nachi [19] (see also Mishra, Singh and Stofile [12]) studied the stability, the $G$-convergence and the $H$-convergence for family of mappings $\left\{T_{n}: X_{n} \rightarrow X\right\}_{n \in \overline{\mathbb{N}}}$. In case that $X$ is a $G$-metric space, we get the corresponding definitions and result. Let $X$ and $Y$ be two nonempty sets and let $T: X \rightarrow Y$ be a mapping. Then the graph of $T$, denoted by $\operatorname{Gr}(T)$, is defined by $G r(T)=\{(x, T x): x \in X\}$.

Definition 1.4. Let $X$ be a $G$-metric space, $\left\{T_{n}: X_{n} \rightarrow X\right\}_{n \in \overline{\mathbb{N}}}$ be a family of mappings, where $\left\{X_{n}\right\}_{n \in \overline{\mathbb{N}}}$ be a family of nonempty subsets $X$. A mapping $T_{\infty}: X_{\infty} \rightarrow X$ is called:

(1) a $\left(\mathrm{G}^{*}\right)$-limit of the sequence $\left\{T_{n}\right\}_{n \in \mathbb{N}}$ or, equivalently $\left\{T_{n}\right\}_{n \in \overline{\mathbb{N}}}$ satisfies the property $\left(\mathrm{G}^{*}\right)$, if $\operatorname{Gr}\left(T_{\infty}\right) \subset \liminf G r\left(T_{n}\right)$.

(2) a $\left(\mathrm{H}^{*}\right)$-limit of the sequence $\left\{T_{n}\right\}_{n \in \mathbb{N}}$ or, equivalently $\left\{T_{n}\right\}_{n \in \overline{\mathbb{N}}}$ satisfies the property $\left(\mathrm{H}^{*}\right)$, if for all sequences $\left\{x_{n}\right\}$ in $\prod_{n \in \mathbb{N}} X_{n}$, we have a sequence $\left\{y_{n}\right\}$ in $X_{\infty}$ with

$$
\lim _{n} G\left(x_{n}, x_{n}, y_{n}\right)=0 \text { and } \lim _{n} G\left(T_{n} x_{n}, T_{n} x_{n}, T_{n} y_{n}\right)=0 .
$$

Now we have the following result as a consequence of the above definition of the $\left(G^{*}\right)$ limit.

Lemma 1.1. Let $X$ be a $G$-metric space. Let $\left\{T_{n}: X_{n} \rightarrow X\right\}_{n \in \overline{\mathbb{N}}}$ be a family of mappings, where $\left\{X_{n}\right\}_{n \in \overline{\mathbb{N}}}$ be a family of nonempty subsets $X$. If a mapping $T_{\infty}: X_{\infty} \rightarrow X$ is a $\left(G^{*}\right)$-limit of the sequence $\left\{T_{n}\right\}_{n \in \mathbb{N}}$, that is, $\operatorname{Gr}\left(T_{\infty}\right) \subset \liminf G r\left(T_{n}\right)$, then, for every $x \in X_{\infty}$, there exists a sequence $\left\{x_{n}\right\}$ in $\prod_{n \in \mathbb{N}} X_{n}$ such that

$$
\lim _{n} G\left(x_{n}, x_{n}, x\right)=0 \text { and } \lim _{n} G\left(T_{n} x_{n}, T_{n} x_{n}, T_{\infty} x\right)=0
$$

Proof. Note that

$$
G r\left(T_{n}\right)=\left\{\left(x_{n}, T_{n} x\right): x_{n} \in X_{n}\right\}, \quad n \in \mathbb{N}
$$

and

$$
\operatorname{Gr}\left(T_{\infty}\right)=\left\{\left(x, T_{\infty} x\right): x \in X_{\infty}\right\}
$$

Therefore

$$
\liminf \operatorname{Gr}\left(T_{n}\right)=\liminf \left\{\left(x_{n}, T_{n} x_{n}\right): x_{n} \in X_{n}\right\},
$$

which implies that

$$
\liminf \operatorname{Gr}\left(T_{n}\right)=\lim _{n \rightarrow \infty}\left[\inf \left\{\left(x_{m}, T_{m} x_{m}\right): x_{m} \in X_{m}\right\}, m \geq n\right]
$$

Moreover, we have

$$
\liminf G\left(T_{n}\right)=\sup \left[\inf \left\{\left(x_{m}, T_{m} x_{m}\right): x_{m} \in X_{m}\right], m \geq n\right]
$$


Hence,

$$
\liminf G\left(T_{n}\right)=\cup_{n=1}^{\infty}\left[\cap_{n=m}^{\infty}\left\{\left(x_{m}, T_{m} x_{m}\right): x_{m} \in X_{m}\right\}\right] .
$$

From (1.4) and (1.5) we have

$$
\text { for all } x \in X_{\infty},\left(x, T_{\infty} x\right) \in \cup_{n=1}^{\infty}\left[\cap_{n=m}^{\infty}\left\{\left(x_{m}, T_{m} x_{m}\right): x_{m} \in X_{m}\right\}\right] \text {, }
$$

which implies that, for all $x \in X_{\infty}$, there exists $n \in \mathbb{N}, m \geq n,\left(x, T_{\infty} x\right)=\left(x_{m}, T_{m} x_{m}\right), x_{m} \in X_{m}$. Thus, for all $x \in X_{\infty}, x_{n} \in \prod_{n \in \mathbb{N}} X_{n}$ such that, for all $m \geq n, x=x_{m}$ and $T_{\infty} x=T_{m} x_{m}$. For every $x \in X_{\infty}$, we have a sequence $\left\{x_{n}\right\}$ in $\prod_{n \in \mathbb{N}} X_{n}$ with

$$
\lim _{n \rightarrow \infty} G\left(x_{n}, x_{n}, x\right)=0 \text { and } \lim _{n \rightarrow \infty} G\left(T_{n} x_{n}, T_{n} x_{n}, T_{\infty} x\right)=0 .
$$

Definition 1.5. Let $X$ be a $G$-metric space. Let $\left\{G_{n}\right\}_{n \in \mathbb{N}}$ a sequence of $G$-metrics on $X$ and Let $\left\{X_{n}\right\}_{n \in \overline{\mathbb{N}}}$ be a family of nonempty subsets of $X$.

(A): For $\left\{x_{n}\right\}_{n \in \mathbb{N}} \in \prod_{n \in \mathbb{N}} X_{n}$ and $x \in X_{\infty}$ such that $\lim _{n} G_{n}\left(x_{n}, x_{n}, x\right)=0$ if and only if $\lim _{n} G\left(x_{n}, x_{n}, x\right)=$ 0.

(A): For $\left\{x_{n}\right\}_{n \in \mathbb{N}} \subset X$ and $x \in X_{\infty}$ such that $\lim _{n} G_{n}\left(x_{n}, x_{n}, x\right)=0$ if and only if $\lim _{n} G\left(x_{n}, x_{n}, x\right)=0$.

(B): For $\left\{x_{n}\right\}_{n \in \mathbb{N}} \in \prod_{n \in \mathbb{N}} X_{n}$, there is $\left\{y_{n}\right\}$ in $X_{\infty}$ such that $\lim _{n} G_{n}\left(x_{n}, x_{n}, y_{n}\right)=0$ if and only if $\lim _{n} G\left(x_{n}, x_{n}, y_{n}\right)=0$.

$\left(\mathbf{B}_{0}\right)$ : For $\left\{x_{n}\right\}_{n \in \mathbb{N}} \subset X$ and $x \in X_{\infty}$ such that $\lim _{n} G_{n}\left(x_{n}, x_{n}, x\right)=0$ if and only if $\lim _{n} G\left(x_{n}, x_{n}, x\right)=0$.

\section{Stability of Fixed Points}

In this section, we present various stability results for $\left\{T_{n}\right\}_{n \in \mathbb{N}}$, a sequence of $(\psi, \varphi)$-weakly contractive mappings in $G$-metric spaces. First, we establish the following result which ensures the existence of the $\left(\mathrm{G}^{*}\right)$-limit.

Proposition 2.1. Let $X$ be a G-metric space and Let $\left\{X_{n}\right\}_{n \in \overline{\mathbb{N}}}$ be a family of nonempty subset of $X$. Suppose that $\left\{T_{n}: X_{n} \rightarrow X_{n}\right\}_{n \in \overline{\mathbb{N}}}$ is sequence of $(\psi, \varphi)$-weakly contractive mappings. If $T_{\infty}: X_{\infty} \rightarrow X$ is a $\left(G^{*}\right)$-limit of a sequence $\left\{T_{n}\right\}$, then $T_{\infty}$ is the unique $\left(G^{*}\right)$-limit of $\left\{T_{n}\right\}$.

Proof. Assume that $T_{\infty}, T_{\infty}^{*}: X_{\infty} \rightarrow X$ are two $\left(G^{*}\right)$-limits of $\left\{T_{n}\right\}$. For $x \in X_{\infty}$, we have two sequences $\left\{x_{n}\right\}$ and $\left\{y_{n}\right\}$ in $\prod_{n \in \mathbb{N}} X_{n}$ such that $\left\{x_{n}\right\}$ and $\left\{y_{n}\right\} G$-converge to $x$ and the sequences $\left\{T_{n} x_{n}\right\}$ and $\left\{T_{n} y_{n}\right\}$ $G$-converge to $T_{\infty} x$ and $T_{\infty}^{*} x$, respectively. Therefore,

$$
G\left(x_{n}, x_{n}, y_{n}\right) \leq G\left(x_{n}, x_{n}, x\right)+G\left(y_{n}, x, x\right) \rightarrow 0 \text { as } n \rightarrow \infty .
$$

Further, one has

$$
G\left(T_{\infty} x, T_{\infty} x, T_{\infty}^{*} x\right) \leq G\left(T_{\infty} x, T_{\infty} x, T_{n} x_{n}\right)+G\left(T_{n} x_{n}, T_{n} x_{n}, T_{n} y_{n}\right)+G\left(T_{n} y_{n}, T_{n} y_{n}, T_{\infty}^{*} x\right) .
$$

Since $T_{n}$ is a $(\psi, \varphi)$-weakly contractive mapping for each $n \in \mathbb{N}$, one has

$$
\psi\left(G\left(T_{n} x_{n}, T_{n} x_{n}, T_{n} y_{n}\right)\right) \leq \psi\left(G\left(x_{n}, x_{n}, y_{n}\right)\right)-\varphi\left(G\left(x_{n}, x_{n}, y_{n}\right)\right)<\psi\left(G\left(x_{n}, x_{n}, y_{n}\right)\right) .
$$

By the monotonicity of $\psi$, we obtain

$$
G\left(T_{n} x_{n}, T_{n} x_{n}, T_{n} y_{n}\right) \leq G\left(x_{n}, x_{n}, y_{n}\right) .
$$


By (2.2), we have

$$
G\left(T_{\infty} x, T_{\infty} x, T_{\infty}^{*} x\right) \leq G\left(T_{\infty} x, T_{\infty} x, T_{n} x_{n}\right)+G\left(x_{n}, x_{n}, y_{n}\right)+G\left(T_{n} y_{n}, T_{n} y_{n}, T_{\infty}^{*} x\right) .
$$

Taking limit as $n \rightarrow \infty$, we obtain $G\left(T_{\infty} x, T_{\infty} x, T_{\infty}^{*} x\right)=0$. This completes the proof.

The following stability result presents a generalization of Fraser and Nadler [6, Theorem 2], and Nachi [19, Theorem 8.4] in $G$-metric spaces.

Theorem 2.1. Let $X$ be a $G$-metric space let and $\left\{X_{n}\right\}_{n \in \overline{\mathbb{N}}}$ be a family of nonempty subset of $X$ equipped with a sequence of generalized metrics $\left\{G_{n}\right\}_{n \in \mathbb{N}}$ satisfying the property (A). Suppose that $\left\{T_{n}: X_{n} \rightarrow\right.$ $\left.X_{n}\right\}_{n \in \overline{\mathbb{N}}}$ is sequence of $(\psi, \varphi)$-weakly contractive mappings on $\left(X_{n}, G_{n}\right) G$-converging in the sense of $\left(G^{*}\right)$ to a $(\psi, \varphi)$-weakly contractive mapping $T_{\infty}: X_{\infty} \rightarrow X$. If $x_{n} \in X_{n}$ is a fixed point of $T_{n}$ for each $n \in \overline{\mathbb{N}}$, and the sequence $\left\{x_{n}\right\}_{n \in \mathbb{N}}$ admits a subsequence $G$-converging to a point $x_{\infty} \in X_{\infty}$, then $x_{\infty}$ is a fixed point of $T_{\infty}$.

Proof. Let $\left\{x_{n_{k}}\right\}$ be a subsequence of $\left\{x_{n}\right\} G$-converging to $x_{\infty}$ in $X_{\infty}$. By property $\left(\mathrm{G}^{*}\right)$, we have a sequence $\left\{y_{n}\right\} \in \prod_{n \in \mathbb{N}} X_{n}$ implies

$$
\lim _{n} G\left(y_{n}, y_{n}, x_{\infty}\right)=0 \text { and } \lim _{n} G\left(T_{n} y_{n}, T_{n} y_{n}, T_{\infty} x_{\infty}\right)=0 .
$$

Using (A), we have

$$
\lim _{n} G_{n}\left(y_{n}, y_{n}, x_{\infty}\right)=0 \text { and } \lim _{n} G_{n}\left(T_{n} y_{n}, T_{n} y_{n}, T_{\infty} x_{\infty}\right)=0 .
$$

If we define a sequence $\left\{z_{n}\right\}$ such that

$$
z_{n_{k}}=x_{n_{k}} \text { for all } k \in \mathbb{N} \text {, and } z_{n}=y_{n} \text { if } n \neq n_{k} \text {, for any } k \in \mathbb{N},
$$

then $\lim _{n} G\left(z_{n}, z_{n}, x_{\infty}\right)=0$. So $\lim _{n} G_{n}\left(z_{n}, z_{n}, x_{\infty}\right)=0$. In view of

$$
G\left(z_{n}, z_{n}, y_{n}\right) \leq G\left(z_{n}, z_{n}, x_{\infty}\right)+G\left(y_{n}, x_{\infty}, x_{\infty}\right) \rightarrow 0 \text { as } n \rightarrow \infty,
$$

we have

$$
\lim _{n} G_{n}\left(z_{n}, z_{n}, y_{n}\right)=0
$$

It follows that

$$
G_{n_{k}}\left(T_{n_{k}} z_{n_{k}}, T_{n_{k}} z_{n_{k}}, T_{\infty} x_{\infty}\right) \leq G_{n_{k}}\left(T_{n_{k}} z_{n_{k}}, T_{n_{k}} z_{n_{k}}, T_{n_{k}} y_{n_{k}}\right)+G_{n_{k}}\left(T_{n_{k}} y_{n_{k}}, T_{n_{k}} y_{n_{k}}, T_{\infty} x_{\infty}\right) .
$$

Since $T_{n_{k}}$ is a $(\psi, \varphi)$-weak contraction on $\left(X_{n}, G_{n}\right)$ for each $k \in \mathbb{N}$, we have

$$
\psi\left(G_{n_{k}}\left(T_{n_{k}} z_{n_{k}}, T_{n_{k}} z_{n_{k}}, T_{n_{k}} y_{n_{k}}\right)\right) \leq \psi\left(G_{n_{k}}\left(z_{n_{k}}, z_{n_{k}}, y_{n_{k}}\right)\right)-\varphi\left(G_{n_{k}}\left(z_{n_{k}}, z_{n_{k}}, y_{n_{k}}\right)\right)<\psi\left(G_{n_{k}}\left(z_{n_{k}}, z_{n_{k}}, y_{n_{k}}\right)\right) .
$$

Since $\psi$ is increasing, we obtain that

$$
G_{n_{k}}\left(T_{n_{k}} z_{n_{k}}, T_{n_{k}} z_{n_{k}}, T_{n_{k}} y_{n_{k}}\right) \leq G_{n_{k}}\left(z_{n_{k}}, z_{n_{k}}, y_{n_{k}}\right)
$$

Using (2.6), we arrive at

$$
G_{n_{k}}\left(T_{n_{k}} z_{n_{k}}, T_{n_{k}} z_{n_{k}}, T_{\infty} x_{\infty}\right) \leq G_{n_{k}}\left(z_{n_{k}}, z_{n_{k}}, y_{n_{k}}\right)+G_{n_{k}}\left(T_{n_{k}} y_{n_{k}}, T_{n_{k}} y_{n_{k}}, T_{\infty} x_{\infty}\right)
$$


Letting $n_{k} \rightarrow \infty$, we have

$$
\begin{aligned}
\lim _{n_{k}} G_{n_{k}}\left(T_{n_{k}} z_{n_{k}}, T_{n_{k}} z_{n_{k}}, T_{\infty} x_{\infty}\right) \leq & \lim _{n_{k}} G_{n_{k}}\left(z_{n_{k}}, z_{n_{k}}, y_{n_{k}}\right) \\
& +\lim _{n_{k}} G_{n_{k}}\left(T_{n_{k}} y_{n_{k}}, T_{n_{k}} y_{n_{k}}, T_{\infty} x_{\infty}\right) \\
= & 0 .
\end{aligned}
$$

Since $T_{n_{k}} x_{n_{k}}=x_{n_{k}}\left(=z_{n_{k}}\right)$ and $x_{n_{k}} \rightarrow x_{\infty}$ as $k \rightarrow \infty$, we obtain that $T_{\infty} x_{\infty}=x_{\infty}$. This completes the proof.

Corollary 2.1. Let $X$ be a $G$-metric space and let $\left\{G_{n}\right\}_{n \in \mathbb{N}}$ a sequence of $G$-metrics on $X$ satisfying the property $\left(A_{0}\right)$. Suppose that $\left\{T_{n}: X \rightarrow X\right\}_{n \in \mathbb{N}}$ is the sequence of $(\psi, \varphi)$-weakly contractive mappings on $\left(X, G_{n}\right) G$-converging in the sense of $\left(G^{*}\right)$ to a mapping $T_{\infty}: X_{\infty} \rightarrow X$. If $x_{n} \in X$ is a fixed point of $T_{n}$ for each $n \in \overline{\mathbb{N}}$, and the sequence $\left\{x_{n}\right\}_{n \in \mathbb{N}}$ admits a subsequence $G$-converging to a point $x_{\infty} \in X_{\infty}$, then $x_{\infty}$ is a fixed point of $T_{\infty}$.

Proof. By taking $X_{n}=X$ for $n \in \overline{\mathbb{N}}$ in Theorem 2.1, we find the desired result immediately.

The following stability result improve and generalizes the results of Fraser and Nadler [6, Theorem 3], and Nachi [19, Theorem 8.5].

Theorem 2.2. Let $X$ be a $G$-metric space and let $\left\{X_{n}\right\}_{n \in \overline{\mathbb{N}}}$ be a family of nonempty subset of $X$ equipped with a sequence of generalized metrics $\left\{G_{n}\right\}_{n \in \mathbb{N}}$ satisfying the property $(A)$. Suppose that $\left\{T_{n}: X_{n} \rightarrow\right.$ $\left.X_{n}\right\}_{n \in \overline{\mathbb{N}}}$ is sequence of $(\psi, \varphi)$-weakly contractive mappings on $\left(X_{n}, G_{n}\right) G$-converging in the sense of $\left(G^{*}\right)$ to a $(\psi, \varphi)$-weakly contractive mapping $T_{\infty}: X_{\infty} \rightarrow X$. If $x_{n} \in X_{n}$ is a fixed point of $T_{n}$ for each $n \in \overline{\mathbb{N}}$, then $\left\{x_{n}\right\}_{n \in \mathbb{N}} G$-converges to $x_{\infty}$.

Proof. Let $x_{\infty}$ be any element in $X_{\infty}$. By $\left(G^{*}\right)$, we have a sequence $\left\{y_{n}\right\}$ in $\prod_{n \in \mathbb{N}} X_{n}$ such that

$$
\lim _{n} G\left(y_{n}, y_{n}, x_{\infty}\right)=0 \text { and } \lim _{n} G\left(T_{n} y_{n}, T_{n} y_{n}, T_{\infty} x_{\infty}\right)=0 .
$$

By property (A), we deduce that

$$
\lim _{n} G_{n}\left(y_{n}, y_{n}, x_{\infty}\right)=0 \text { and } \lim _{n} G_{n}\left(T_{n} y_{n}, T_{n} y_{n}, T_{\infty} x_{\infty}\right)=0 .
$$

By the monotonicity of $\psi$ and (2.9), we get

$$
\begin{aligned}
\lim _{n} \psi\left(G_{n}\left(x_{n}, x_{n}, x_{\infty}\right)\right) & \leq \lim _{n} \psi\left(G_{n}\left(T_{n} x_{n}, T_{n} x_{n}, T_{\infty} x_{\infty}\right)\right) \\
& \leq \lim _{n} \psi\left(G_{n}\left(T_{n} x_{n}, T_{n} x_{n}, T_{n} y_{n}\right)+G_{n}\left(T_{n} y_{n}, T_{n} y_{n}, T_{\infty} x_{\infty}\right)\right) \\
& =\lim _{n} \psi\left(G_{n}\left(T_{n} x_{n}, T_{n} x_{n}, T_{n} y_{n}\right)\right) .
\end{aligned}
$$

Since $T_{n}$ is a $(\psi, \varphi)$-weakly contractive on $\left(X_{n}, G_{n}\right)$ and $\lim _{n} G\left(y_{n}, y_{n}, x_{\infty}\right)=0$, we have

$$
\begin{aligned}
& \lim _{n} \psi\left(G_{n}\left(T_{n} x_{n}, T_{n} x_{n}, T_{n} y_{n}\right)\right) \\
& \leq \lim _{n} \psi\left(G_{n}\left(x_{n}, x_{n}, y_{n}\right)\right)-\varphi\left(G_{n}\left(x_{n}, x_{n}, y_{n}\right)\right) \\
& \leq \lim _{n} \psi\left(G_{n}\left(x_{n}, x_{n}, x_{\infty}\right)+G_{n}\left(y_{n}, y_{n}, x_{\infty}\right)\right)-\lim _{n} \varphi\left(G_{n}\left(x_{n}, x_{n}, y_{n}\right)\right) \\
& \leq \lim _{n} \psi\left(G_{n}\left(x_{n}, x_{n}, x_{\infty}\right)\right)-\lim _{n} \varphi\left(G_{n}\left(x_{n}, x_{n}, y_{n}\right)\right) \\
& \leq \lim _{n} \psi\left(G_{n}\left(x_{n}, x_{n}, x_{\infty}\right)\right) .
\end{aligned}
$$


Let $\lim _{n} G\left(x_{n}, x_{n}, x_{\infty}\right)=t$, for $t \in \mathbb{R}_{+}$. If $t=0$, then it is done. If $t>0$, then we find from (2.10) and (2.11) that

$$
\psi(t) \leq \psi(t)-\lim _{n} \varphi\left(G_{n}\left(x_{n}, x_{n}, y_{n}\right)\right)
$$

which implies $\lim _{n} \varphi\left(G_{n}\left(x_{n}, x_{n}, y_{n}\right)\right)=0$, a contradiction. Hence, $\lim _{n} G\left(x_{n}, x_{n}, x_{\infty}\right)=0$, that is, $\left\{x_{n}\right\}_{n \in \mathbb{N}}$ $G$-converges to $x_{\infty}$.

Corollary 2.2. Let $X$ be a $G$-metric space and let $\left\{G_{n}\right\}_{n \in \mathbb{N}}$ a sequence of $G$-metrics on $X$ satisfying the property $\left(A_{0}\right)$. Suppose that $\left\{T_{n}: X \rightarrow X\right\}_{n \in \mathbb{N}}$ is the sequence of $(\psi, \varphi)$-weakly contractive mappings on $\left(X, G_{n}\right) G$-converging to a mapping $T_{\infty}: X_{\infty} \rightarrow X$. If $x_{n} \in X$ is a fixed point of $T_{n}$ for each $n \in \overline{\mathbb{N}}$, then $\left\{x_{n}\right\}_{n \in \mathbb{N}} G$-converges to $x_{\infty}$.

Proof. By taking $X_{n}=X$ for $n \in \overline{\mathbb{N}}$ in Theorem 2.2, we find the desired conclusion easily.

Theorem 2.3. Let $X$ be a G-metric space and let $\left\{X_{n}\right\}_{n \in \overline{\mathbb{N}}}$ be a family of nonempty subset of $X$ equipped with a sequence of generalized metrics $\left\{G_{n}\right\}_{n \in \mathbb{N}}$ satisfying the property $(B)$. Suppose that $\left\{T_{n}: X_{n} \rightarrow\right.$ $\left.X_{n}\right\}_{n \in \overline{\mathbb{N}}}$ is sequence of mappings on $\left(X_{n}, G_{n}\right)$ satisfies the property $\left(H^{*}\right)$ and $G$-converging to a $(\psi, \varphi)$ weakly contractive mapping $T_{\infty}: X_{\infty} \rightarrow X$. If $x_{n} \in X_{n}$ is a fixed point of $T_{n}$ for each $n \in \overline{\mathbb{N}}$, then $\left\{x_{n}\right\}_{n \in \mathbb{N}}$ $G$-converges to $x_{\infty}$.

Proof. By $\left(H^{*}\right)$, we find a sequence $\left\{y_{n}\right\}$ in $X_{\infty}$ having

$$
\lim _{n} G\left(x_{n}, x_{n}, y_{n}\right)=0 \text { and } \lim _{n} G\left(T_{n} x_{n}, T_{n} x_{n}, T_{\infty} y_{n}\right)=0 .
$$

Using property (B), we obtain

$$
\lim _{n} G_{n}\left(x_{n}, x_{n}, y_{n}\right)=0 \text { and } \lim _{n} G_{n}\left(T_{n} x_{n}, T_{n} x_{n}, T_{\infty} y_{n_{n}}\right)=0 .
$$

By the monotonicity of $\psi$ and (2.12), we have

$$
\psi\left(G_{n}\left(x_{n}, x_{n}, x_{\infty}\right)\right) \leq \psi\left(G_{n}\left(T_{n} x_{n}, T_{n} x_{n}, T_{\infty} y_{n}\right)+G_{n}\left(T_{\infty} y_{n}, T_{\infty} y_{n}, T_{\infty} x_{\infty}\right)\right) \leq \psi\left(G_{n}\left(T_{\infty} y_{n}, T_{\infty} y_{n}, T_{\infty} x_{\infty}\right)\right) .
$$

As $T_{\infty}$ is $(\psi, \varphi)$-weakly contractive, we see that

$$
\begin{aligned}
\lim _{n} \psi\left(G_{n}\left(T_{\infty} y_{n}, T_{\infty} y_{n}, T_{\infty} x_{\infty}\right)\right) \leq & \lim _{n} \psi\left(G_{n}\left(y_{n}, y_{n}, x_{\infty}\right)\right)-\lim _{n} \varphi\left(G_{n}\left(y_{n}, y_{n}, x_{\infty}\right)\right) \\
\leq & \lim _{n} \psi\left(G_{n}\left(y_{n}, y_{n}, x_{n}\right)+G_{n}\left(x_{n}, x_{n}, x_{\infty}\right)\right) \\
& -\lim _{n} \varphi\left(G_{n}\left(y_{n}, y_{n}, x_{\infty}\right)\right) \\
\leq & \lim _{n} \psi\left(G_{n}\left(x_{n}, x_{n}, x_{\infty}\right)\right)-\lim _{n} \varphi\left(G_{n}\left(y_{n}, y_{n}, x_{\infty}\right)\right) \\
\leq & \lim _{n} \psi\left(G_{n}\left(x_{n}, x_{n}, x_{\infty}\right)\right) .
\end{aligned}
$$

Let $\lim _{n} G\left(x_{n}, x_{n}, x_{\infty}\right)=t$, for $t \in \mathbb{R}_{+}$. If $t=0$, then it is done. If $t>0$, then we find from (2.13) and (2.14) that

$$
\psi(t) \leq \psi(t)-\lim _{n} \varphi\left(G_{n}\left(y_{n}, y_{n}, x_{\infty}\right)\right)
$$

which implies that $\lim _{n} \varphi\left(G_{n}\left(y_{n}, y_{n}, x_{\infty}\right)\right)=0$. Hence, $\lim _{n} G\left(x_{n}, x_{n}, x_{\infty}\right)=0$, that is, $\left\{x_{n}\right\}_{n \in \mathbb{N}} G$-converges to $x_{\infty}$. 
Corollary 2.3. Let $X$ be a G-metric space and let $\left\{G_{n}\right\}_{n \in \mathbb{N}}$ a sequence of G-metrics on $X$ satisfying the property $\left(B_{0}\right)$. Suppose that $\left\{T_{n}: X \rightarrow X\right\}$ is a sequence of mappings on $\left(X, G_{n}\right) G$-converging to $a(\psi, \varphi)$-weakly contractive mapping $T_{\infty}: X \rightarrow X$. If $x_{n} \in X$ is a fixed point of $T_{n}$ for each $n \in \overline{\mathbb{N}}$, then $\left\{x_{n}\right\}_{n \in \mathbb{N}}$ G-converges to $x_{\infty}$.

Proof. By taking $X_{n}=X$ for all $n \in \overline{\mathbb{N}}$ in Theorem 2.3, we obtain the desired conclusion immediately.

\section{REFERENCES}

[1] M. Abbas, T. Nazir, S. Radenovic, Some periodic point results in generalized metric spaces, Appl. Math. Comput. 217 (2010), 4094-4099.

[2] L. Barbet, K. Nachi, Sequences of contractions and convergence of fixed points, Monografias del Seminario Matemático Garcia de Galdeano 33 (2006), 51-58.

[3] L. Barbet, K. Nachi, Convergence des points fixes de $k$-contractions (convergence of fixed points of $k$-contractions), Preprint, University of Pau, (2006).

[4] F.F. Bonsall, Lectures on Some Fixed Point Theorems of Functional Analysis, Tata Institute of Fundamental Research, Bombay, 1962.

[5] R. Chugh, T. Kadian, A. Rani, B.E. Rhoades, Property $p$ in $G$-metric spaces, Fixed Point Theory Appl. 2010 (2010), Article ID 401684.

[6] R.B. Fraser, S.B. Nadler, Sequences of contractive maps and fixed points, Pacific J. Math. 31 (1969), 659-667.

[7] N. Hussain, A. Latif, P. Salimi, Best proximity point results in G-metric spaces, Abst. Appl. Anal. 2014 (2014), Article ID 837943.

[8] N. Hussain, A. Latif, P. Salimi, New fixed point results for contractive maps involving dominating auxiliary functions, J. Nonlinear Sci. Appl. 9 (2016), 4114-4126

[9] S. Mishra, A. K. Kalinde, On certain stability results of Barbet and Nachi, Fixed Point Theory 12 (2011), 137-144.

[10] S.N Mishra, R. Pant, Sequences of $\varphi$-contractions and stability of fixed points, Indian J. Math. 54 (2012), 211-223.

[11] S. Mishra, S.L. Singh, R. Pant, Some new results on stability of fixed points, Chaos, Soliton Fractals 45 (2012), $1012-1016$.

[12] S. Mishra, S.L. Singh, S. Stofile, Stability of common fixed points in uniform spaces, Fixed Point Theory Appl. 2011 (2011), Article ID 37.

[13] Z. Mustafa, B. Sims, Some remarks concerning D-metric spaces. In: Proceedings of the International Conferences on Fixed Point Theory and Applications (Valencia, Spain), pp. 189-198 (2003)

[14] Z. Mustafa, B. Sims, A new approach to generalized metric spaces, J. Nonlinear Convex Anal. 7 (2006), $289-297$.

[15] Z. Mustafa, H. Obiedat, F. Awawdeh, Some fixed point theorem for mapping on complete $G$-metric spaces, Fixed Point Theory Appl. 2008 (2008), Article ID 189870.

[16] Z. Mustafa, B. Sims, Fixed point theorems for contractive mapping in complete $G$-metric spaces, Fixed Point Theory Appl. 2009 (2009), Article ID 917175.

[17] Z. Mustafa, W. Shatanawi, M. Bataineh, Existence of fixed point results in G-metric spaces, Int. J. Math. Math. Sci. 2009 (2009), Article ID 283028.

[18] Z. Mustafa, F. Awawdeh, W. Shatanawi, Fixed point theorem for expansive mappings in $G$-metric spaces, Int. J. Contemp. Math. Sci. 5 (2010), 2463-2472.

[19] K. Nachi, Sensibileté et stabilité de points fixes et de solutions d'inclusions, Thesis, University of Pau, 2006.

[20] R. Saadati, S.M. Vaezpour, P. Vetro, B.E. Rhoades, Fixed point theorems in generalized partially ordered $G$-metric spaces, Math. Comput. Model. 52 (2010), 797-801.

[21] S.B. Nadler, Jr., Sequences of contractions and fixed points, Pacific J. Math. 27 (1968), 579-585.

[22] W. Shatanawi, Fixed point theory for contractive mappings satisfying $\Phi$-maps in $G$-metric spaces, Fixed Point Theory Appl. 2010 (2010), Article ID 181650. 